\title{
Trifluoperazine induces apoptosis through the upregulation of Bax/Bcl-2 and downregulated phosphorylation of AKT in mesangial cells and improves renal function in lupus nephritis mice
}

\author{
BAODONG WANG, YANKUN LUO, XIAOSHUANG ZHOU and RONGSHAN LI
}

\author{
Department of Nephrology, The Affiliated People's Hospital of Shanxi Medical University, \\ Shanxi Provincial People's Hospital, Shanxi Kidney Disease Institute, Taiyuan, Shanxi 030001, P.R. China
}

Received May 29, 2017; Accepted January 10, 2018

DOI: $10.3892 /$ ijmm.2018.3562

\begin{abstract}
The inhibition of mesangial cell (MC) proliferation has become an important therapy in preventing glomerular proliferation diseases. Trifluoperazine (TFP) has been reported to inhibit the proliferation of several types of cancer cell, however, the effects of TFP in renal proliferation diseases remain to be fully elucidated. The present study examined the effects of TFP on the proliferation of MCs and quantified cell apoptosis progression in vivo and in vitro. The effects of various TFP concentrations and treatment durations on cell proliferation and cell apoptosis in vitro were analyzed using flow cytometry in conjunction with a Cell Counting kit-8 assay. Cell proliferation in vivo was determined using hematoxylin and eosin staining and immunohistochemistry of Ki67. The expression of the two cell apoptosis-related proteins, B-cell lymphoma-2 (Bcl-2) and Bcl-2-associated $\mathrm{X}$ protein (Bax), were estimated using western blot analysis and immunohistochemistry in vivo and in vitro. TFP-induced phosphatidylinositol 3-kinase (PI3K)/protein kinase B (AKT) signaling pathways were also estimated using western blot analysis. These results suggested that TFP inhibited MC proliferation in a dose- and time-dependent manner. It was found that TFP inhibited the abnormal proliferation of MCs, which was stimulated by $20 \%$ fetal bovine serum in vitro and in lupus MRL/lpr mice. TFP promoted cell apoptosis, downregulated the expression of Bcl-2 and upregulated the expression of Bax in a dose-dependent manner at mRNA and protein levels. In addition, TFP inhibited phosphorylated AKT, potentially leading to the suppressed activation of PI3K/AKT signaling
\end{abstract}

Correspondence to: Professor Rongshan Li, Department of Nephrology, The Affiliated People's Hospital of Shanxi Medical University, Shanxi Provincial People's Hospital, Shanxi Kidney Disease Institute, 29 Shuang Ta East Street, Taiyuan, Shanxi 030001, P.R. Chinaa

E-mail: rongshanli13@163.com

Key words: trifluoperazine, mesangial cells, proliferation, cell apoptosis, protein kinase B pathways. TFP treatment significantly decreased the levels of blood urea nitrogen and serum creatinine, but had no significant effects on the body weight and liver function of the lupus mice. These results validated and reinforced the potential of TFP in the treatment of mesangial proliferative diseases.

\section{Introduction}

Mesangial cells (MCs) are essential in physiological functions, including the regulation of intraglomerular capillary flow, phagocytosis and removal of foreign bodies, secretion of cytokines, and generation of extracellular matrix (ECM) (1). However, these cells are vulnerable to the effect of various stimuli, which can give rise to kidney damage by releasing inflammatory factors and ECM components, ultimately leading to glomerular sclerosis and interstitial fibrosis. Patients suffering the effects of these diseases experience the development of end-stage renal disease after several years owing to renal fibrosis $(2,3)$. Therefore, the inhibition of MC proliferation has become an important therapy in treating glomerular proliferative diseases. MRL/lpr lupus nephritis (LN) in mice is characterized by the activation of MCs in the kidney leading to the uncontrolled release of inflammatory mediators. The renal pathology of LN in mice includes the proliferation of MCs and thickening of the mesangial matrix at the age of 24 weeks (4). Therefore, MRL/lpr LN mice are well recognized as a representative pathological model of human MC proliferative nephropathy $(5,6)$.

Apoptosis, a specialized form of cellular suicide, is important in a broad range of physiological functions, including cell growth, morphogenesis, tissue homeostasis and immunity. Members of the B-cell lymphoma-2 (Bcl-2) family of proteins are essential in regulating apoptosis (7-9). The effects of Bcl-2, $\mathrm{Bcl}$-extra large (xL) and $\mathrm{Bcl}-2$-associated $\mathrm{X}$ protein (Bax) proteins on the regulation of $\mathrm{MC}$ apoptosis in vivo and in vitro have been investigated previously. It has been suggested that expression levels of Bcl-2 and Bcl-xL in MCs are positively correlated with the downregulation of apoptosis, whereas the overexpression of Bax protein facilitates a process of apoptosis (10-12). This suggests that the regulation of intrinsic targets, including the $\mathrm{Bcl}-2$ family of proteins, is a potential strategy for the development of MC anti-proliferation agents. 
An intracellular signaling pathway implicated in the regulation of apoptosis is the protein kinase $\mathrm{B}$ (AKT) cascade $(13,14)$. AKT is mainly activated by growth factors, and is associated with cell proliferation, differentiation and cell death. Gong et al (15) reported that aplysin inhibits cell proliferation and induces apoptosis in vitro, possibly through suppressing the phosphatidylinositol 3-kinase (PI3K)/AKT pathway. In vivo, the tissues of AKT1-knockout mice with increased apoptosis was smaller, compared with the tissues of wild-type littermates (16). In LN mice, MC proliferation has been shown to be a critical event, in which the phosphorylation of AKT becomes overexpressed (17). These data suggest that the abnormal proliferation of MCs may be associated with the inhibition of apoptosis induced by the expression of overactive AKT.

Trifluoperazine (TFP) is a calmodulin inhibitor, and a classic anxiolytic and antipsychotic drug. Previous investigations have demonstrated that TFP can arrest cell cycle, inhibit cell proliferation and induce apoptosis. Previous studies have reported that TFP suppressed the proliferation of fibrosarcoma HT1080, leukemia, breast cancer and human A549 lung adenocarcinoma cells by regulating different signaling pathways (18-20). Yeh et al (21) reported that TFP inhibited cancer stem cell proliferation by suppressing the apoptotic pathway. However, the role and mechanism of TFP in MC remain to be fully elucidated.

The present study aimed to investigate the effects of TFP on the progression of cell proliferation and cell apoptosis in an MC line in vivo and in vitro.

\section{Materials and methods}

Animals. A total of 10 six-week-old female C57BL/6 mice weighing $\sim 20 \pm 5 \mathrm{~g}$ were purchased from the Experimental Animal Center of Shanxi Medical University (Taiyuan, China); 20 female MRL/lpr LN mice ( 22 +5 g, 8-weeks-old) were purchased from the Model Animal Institute of Nanjing University (induced from Jackson Laboratory, Ben Harbor, ME, USA). The mice were housed under controlled pathogen-free environmental conditions (temperature $22^{\circ} \mathrm{C}, 12 \mathrm{~h}$ light-dark cycle). Animals were given free access to water and fed a standard laboratory diet. The experiments were performed according with protocols approved by the Institutional Animal Care and Use Committee of Shanxi Medical University.

Treatment protocols. The mice were randomly divided into three groups (n=6/group): Control group, LN group, and LN+TFP group. The animals in the LN+TFP group were intraperitoneally injected with $20 \mathrm{mg} / \mathrm{kg} \cdot$ day TFP (Sigma-Aldrich; Merck Millipore, Darmstadt, Germany) at 12 weeks of age. The mice in the LN group received the same injection ratio, but of saline. After 12 weeks, the animals were sacrificed. Peripheral blood and kidney samples were obtained, and the renal samples were embedded in paraffin for histopathological and immunohistochemical analysis. Additional renal tissue was acquired and immediately frozen in liquid nitrogen until analysis.

Immunohistochemistry. The renal samples were fixed in $10 \%$ formalin at room temperature for $>48 \mathrm{~h}$ and embedded in paraffin. Serial 5- $\mu \mathrm{m}$ sections were deparaffinized in xylene and rehydrated using sequential passage with 100, 95, 80 and $70 \%$ ethanol for $10 \mathrm{~min}$ each followed by three washes with distilled water. Unspecific staining was blocked with $1.5 \%$ standard goat serum (ab138478; Abcam, Cambridge, UK) for $15 \mathrm{~min}$ at room temperature and then incubated at $4^{\circ} \mathrm{C}$ overnight with 1:100 diluted primary Ki67 antibodies (sc-23900; Santa Cruz Biotechnology, Inc., Dallas, TX, USA). Sections maintained in PBS were used as a negative control. The tissue was incubated with a pre-diluted horseradish peroxidase-conjugated secondary antibody (PV-9000; ZSGB-BIO Technology, Co., Ltd., Beijing, China) for $1 \mathrm{~h}$ at room temperature. The immunohistochemical analysis was performed in a blinded manner by two independent investigators. Mice glomeruli (10 per mouse) were examined in a blinded manner at each time point using high-power light microscopy (magnification, x400). ImageJ software 6.0 (National Institutes of Health, Bethesda, MD, USA) was used to quantitatively count the number of Ki67-positive cells and total glomerular cells. Ki67 relative density was calculated as the ratio of Ki67-positive cells to total glomerular cells.

$H \& E$ staining. The formalin-fixed tissue was embedded in paraffin, and sections of 5- $\mu \mathrm{m}$ thickness were cut, deparaffinized in xylene and rehydrated in a descending alcohol series. The sections were conducted via sequential passage. Sections were stained with hematoxylin for $5 \mathrm{~min}$ at room temperature, differentiated in $1 \%$ acid alcohol for $30 \mathrm{sec}$, blued in $0.2 \%$ ammonia water for $30 \mathrm{sec}$ and subsequently stained with eosin for $15 \mathrm{sec}$ at room temperature. Mice glomeruli (10 per mouse) were obtained in a blinded manner at each time point using high-power light microscopy (magnification, x400). ImageJ software 6.0 (National Institutes of Health) was used to count the number of mesangial cells.

Cell culture and treatments. The T-SV40 (22) human mesangial cell line was donated by Dr Xuewang Li of Peking Union Medical College Hospital (Beijing, China). The cells were cultured in RMPI-1640 medium (HyClone; GE Healthcare Life Sciences, Logan, UT, USA) containing $10 \%$ fetal bovine serum (FBS; GE Healthcare Life Sciences) at $37^{\circ} \mathrm{C}$ with $5 \% \mathrm{CO}_{2}$. The cells at $\sim 70 \%$ confluence were planted in serum-free medium for $24 \mathrm{~h}$, and treated with 10 and $20 \%$ FBS as control and model groups, respectively. Different concentrations of TFP $(0,5,10,20$ and $30 \mu \mathrm{M})$ were added to the corresponding groups. Another grouping method in the present study comprised normal cells, which were treated with $20 \mathrm{ng} / \mathrm{ml}$ platelet-derived growth factor (PDGF; PeproTech, Inc. Rocky Hill, NJ, USA), and cells treated with PDGF and $20 \mu \mathrm{M}$ TFP (PDGF+TFP) to detect the AKT signaling pathway.

Cell counting kit-8 (CCK-8) assay and cell counting. The MCs were grown at a density of $5 \times 10^{3}$ cells/well in 96-well plates and cell viability was assessed using a CCK-8 assay (Beyotime Institute of Biotechnology, Jiangsu, China) in accordance with the manufacturer's protocols. The cells were grown in 96-well plates at a density of $10^{6}$ cells/well and treated with 10 or $20 \%$ FBS and different concentrations of TFP $(0,5,10,20$ and $30 \mu \mathrm{M}$ ) for $24 \mathrm{~h}$. Following the relative treatment, $10 \mu \mathrm{l} \mathrm{CCK}-8$ solution was added to each well, and the cells in the plate were 
incubated at $37^{\circ} \mathrm{C}$ for $2 \mathrm{~h}$ The absorbance was measured at a test wavelength of $450 \mathrm{~nm}$ and a reference wavelength of $650 \mathrm{~nm}$ on an automated reader (Bio-Rad Model 550; Bio-Rad Laboratories, Inc., Hercules, CA, USA). Cell survival was calculated according the optical density (OD) as a percentage using the following formula: Cell survival $(\%)=($ mean OD of treated cells/mean OD of control cells) x100. The results were calculated as a percentage of the untreated control cells. For cell counting, the MCs were seeded into 24-well plates at a density of $1 \times 10^{5}$ cells per well. Following treatment, the cells were harvested and counted. The living cell population was estimated using a trypan blue dye exclusion test; cells were counted under a low-power light microscope (magnification, $\mathrm{x} 40$ ).

Flow cytometric analysis of apoptosis. The effects of TFP on cell apoptosis were analyzed using flow cytometry. The cells were treated with 10 or $20 \%$ FBS and TFP $(0,5,10$ and $20 \mu \mathrm{M}$ ) for $24 \mathrm{~h}$. The cells were then centrifuged at $447.2 \mathrm{x} \mathrm{g}$ and $4^{\circ} \mathrm{C}$ for $10 \mathrm{~min}$ and washed twice with PBS. The supernatant was then discarded and the cells were processed with an Annexin V/PI staining apoptosis detection kit (Aria II; BD Biosciences, Franklin Lakes, NJ, USA) according to the manufacturer's protocols. The cells were separated into three groups: Viable, early apoptotic, and late apoptotic or dead. Viable cells exhibit only weak Annexin V staining of the cellular membrane, whereas early apoptotic cells exhibit a significantly higher degree of surface labeling. Late apoptotic or dead cells exhibit membrane staining by Annexin V and marked nuclear staining by propidium iodide. Following staining, cell apoptosis was analyzed by the number of early apoptotic cells using a flow cytometer (Beckman Coulter, Inc., Palo Alto, CA, USA).

Reverse transcription-quantitative polymerase chain reaction $(R T-q P C R)$ analysis. Total RNA was extracted from the MCs or mouse tissues independently using TRIzol reagent (Invitrogen; Thermo Fisher Scientific, Inc.) according to the manufacturer's protocols. The spectrophotometer (Thermo Fisher Scientific, Inc.) was used to measure the concentration of RNA in each sample. Total RNA ( $2 \mu \mathrm{g})$ was reverse transcribed to cDNA using a reverse transcription kit (Takara Bio, Inc., Otsu, Japan). The qPCR analysis was performed using SYBR Premix Ex Taq (2X) (RR820A; Takara Bio, Inc.). A total of $2 \mu \mathrm{l}$ cDNA (<100 ng), $10 \mu \mathrm{l}$ buffer, $0.3 \mu \mathrm{l}$ forward primer, $0.3 \mu \mathrm{l}$ reverse primer and double-distilled water $\left(\mathrm{ddH}_{2} \mathrm{O}\right) \leq 20 \mu$ l. The qPCR thermal cycling protocol was programmed in the CFX96 ${ }^{\mathrm{TM}}$ Real-Time PCR Detection system (Bio-Rad Laboratories, Inc.) and consisted of an initial denaturation step at $95^{\circ} \mathrm{C}$ for $30 \mathrm{sec}$, followed by 40 cycles of denaturation for $5 \mathrm{sec}$ at $95^{\circ} \mathrm{C}$, and annealing and extension for $30 \mathrm{sec}$ at $56^{\circ} \mathrm{C}$. The $\beta$-actin (mouse tissue) or GAPDH (MC cell) gene was used as the internal control. The primers used for mouse tissues were as follows: Bcl-2 forward, 5'-CTTCAGGGATGG GGTGAACT-3' and reverse, 5'-CAGCCTCCGTTATCCTGG AT-3'; Bax forward, 5'-TCATGAAGACAGGGGCCTTT-3' and reverse, 5'-GTCCACGTCAGCAATCATCC-3'; $\beta$-actin forward, 5'-CCTCTATGCCAACACAGTGC-3' and reverse, 5'-CCT GCTTGCTGATCCACATC-3'. The primes for MCs were as follows: Bax forward, 5'-AAGCTGAGCGAGTGTCTCAAG-3' and reverse, 5'-CAAAGTAGAAAGGGCGACAAC-3'; Bcl-2 forward, 5'-TGGGAGAACAGGGTACGATAAC-3' and reverse, 5'-GAACTCAAAGAAGGCCACAATC-3'; GAPDH forward, 5'-GGGAAACTGTGGCGTGAT-3' and reverse, 5'-GAGTGG GTGTCGCTGTTGA-3'. The mRNA levels were normalized to internal control and assessed using the $2^{-\Delta \Delta C q}$ method (23).

Western blot analysis. The MCs or kidney tissue were lysed in radioimmunoprecipitation assay lysis buffer (Beyotime Institute of Biotechnology) and centrifuged at 14,000 x g for $10 \mathrm{~min}$ at $4^{\circ} \mathrm{C}$. The protein was collected and concentration was determined using a BCA assay kit (Nanjing KeyGen Biotech Co., Ltd., Nanjing, China). Samples containing $60 \mu \mathrm{g}$ of protein were resolved via $12 \%$ SDS-PAGE and transferred onto nitrocellulose membranes (Whatman International, Ltd., Maidstone, UK). Following blocking with 5\% skimmed milk powder in Tris-buffered saline $(50 \mathrm{mmol} / \mathrm{l}$ Tris-base and $\mathrm{NaCl}$ ) and $0.1 \%$ Tween-20 at room temperature for $70 \mathrm{~min}$, the membranes were incubated with the following primary antibodies overnight at $4^{\circ} \mathrm{C}$ : Bcl-2 (cat. no. SC-492), Bax (cat. no. SC-526), phosphorylated (p-)AKT/Thr308 (p-AKT) (cat. no. SC-16646-R), AKT (cat. no. SC-8312) and $\beta$-actin (sc-4967S) antibodies (dilution 1:200) from Santa Cruz Biotechnology, Inc. Following being washed three times for 15 min with TBST buffer, the membranes were incubated with a corresponding horseradish peroxidase-conjugated secondary antibody (1:5,000, ZB-5301; ZSGB-BIO Technology, Co., Ltd.) for $1 \mathrm{~h}$ at room temperature and analyzed using the Quantity One analysis system, version 4.62 version (Bio-Rad Laboratories, Inc.)

Measurement of renal and liver function. Blood urea nitrogen (BUN) and serum creatinine $(\mathrm{Cr})$, two key renal function markers, were determined with commercially available kits according to the manufacturer's protocols (cat. nos. KA0201 and KA0314, respectively; Shanghai Yuanye Science and Technology Co., Ltd., Shanghai, China). The observation absorbance was read at $450 \mathrm{~nm}$. The same ELISA procedure was used for aspartate aminotransferase (AST), a key liver function marker (cat. no. KA0565; Shanghai Yuanye Science and Technology Co., Ltd.) according to the manufacturer's protocols.

Statistics analysis. The statistical analyses were performed with SPSS 19.0 (IBM SPSS, Armonk, NY, USA). The values are expressed as the mean \pm standard deviation. Data analyses were performed using one-way analysis of variance tests followed by two-tailed t-test post-hoc comparisons. $\mathrm{P}<0.05$ was considered to indicate a statistically significant difference.

\section{Results}

TFP reduces $M C$ proliferation in vitro. The CCK- 8 assay showed time- and dose-dependent inhibition of MC proliferation elicited by TFP. With an increased concentration of TFP and duration of treatment, the percentage of viable cells was significantly decreased, particularly following treatment with $20 \mu \mathrm{M}$ TFP (Fig. 1A and B). The results of the CCK-8 assay were reinforced using the cell counting assay. Proliferation of the cells in response to TFP was significantly inhibited in a time- and dose-dependent manner in the MCs (Fig. 1C). 

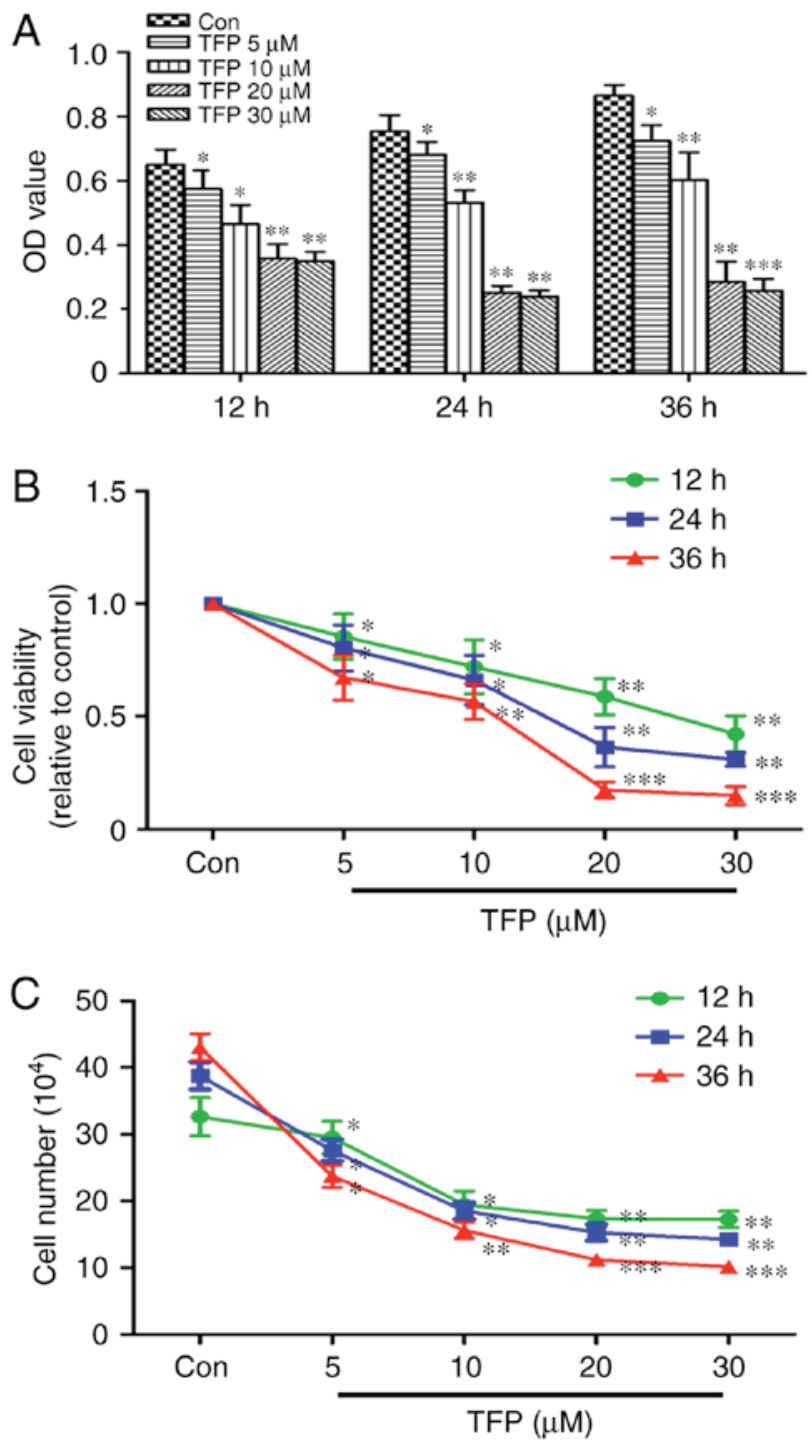

Figure 1. TFP inhibits the proliferation of MCs. MCs were treated with various concentrations $(5,10,20$ and $30 \mu \mathrm{M})$ of TFP for the indicated durations (12, 24 and $36 \mathrm{~h}$ ). (A) Cell viability was assessed using a cell counting kit-8 assay. (B) Percentage cell survival was calculated as follows: Cell survival $(\%)=(\mathrm{OD}$ treated cells/OD cells with vehicle solvent $) \times 100$. (C) Cell counting assays were performed to plot cell viability. All data are presented as the mean \pm standard deviation of six separate experiments $(n=6) .{ }^{*} P<0.05$, ${ }^{* *} \mathrm{P}<0.01$ and ${ }^{* * *} \mathrm{P}<0.001$, vs. con. MCs, mesangial cells; TFP, trifluoperazine; con, control; OD, optical density.

TFP promotes $M C$ apoptosis in vitro. To examine whether TFP treatments induced apoptosis, the MCs were treated with various concentrations of TFP for $24 \mathrm{~h}$. The results of flow cytometry showed that TFP treatments induced a significant increase in of Annexin V-positive cell populations in a dose-dependent manner (Fig. 2A). In the experiment, Bcl-2 and Bax were the two important apoptosis-related proteins regulating cellular apoptosis. It was observed that TFP (5, 10 and $20 \mu \mathrm{M})$ treatment decreased the level of $\mathrm{Bcl}-2$ and increased the expression of Bax in a dose-dependent manner. This was observed at the gene and protein levels (Fig. 2B and C).

TFP suppresses $20 \%$ FBS-stimulated MC proliferation. The present study demonstrated that TFP inhibited the proliferation of normal MCs by promoting cellular apoptosis. Subsequently,
MC proliferation was stimulated with exogenous factors (20\% FBS), and whether TFP inhibited this effect was examined. The results revealed that, following treatment with $20 \%$ FBS, the proliferation rate of the cultured MCs was significantly increased, compared with that of the $10 \%$ FBS-treated MCs $(\mathrm{P}<0.05)$. Following TFP treatment, the proliferation rate of MCs cultured with 20\% FBS was significantly lower, compared with that in the $20 \%$ FBS control group $(\mathrm{P}<0.05$; Fig. 3A). Compared with the $20 \%$ FBS group, the apoptotic rates were lower in the normal $(10 \% \mathrm{FBS})$ group and increased following TFP treatment (Fig. 3B). Compared with the $20 \%$ FBS control group, the protein levels of $\mathrm{Bcl}-2$ were significantly decreased in the $20 \%$ FBS-cultured MC following TFP treatment $(\mathrm{P}<0.05)$, whereas the expression of Bax was higher in the TFP-treated cells, compared with that in the control group (Fig. 3C).

TFP promotes MC apoptosis in vivo. In order to further examine whether TFP inhibits the proliferation of MCs by inducing MC apoptosis in vivo, the present study measured cell proliferation rates, and levels of apoptosis-related factors Bcl-2 and Bax in the kidney tissues of mice. H\&E staining indicated diffuse proliferation of MCs and the glomerular matrices of LN mice, compared with the control, which decreased following treatment with TFP for 3 months (Fig. 4A). The results of $\mathrm{Ki}-67$ immunohistochemical analysis confirmed these findings (Fig. 4B). The apoptosis-related proteins Bcl-2 and Bax in the kidney tissue were also detected using western blot analysis. Compared with those in the normal group, the expression levels of anti-apoptotic Bcl-2 and pro-apoptotic Bax were increased. However, the $\mathrm{Bax} / \mathrm{Bcl}-2$ ratio was decreased in the LN group. Compared with the LN group, the expression of Bcl-2 was decreased whereas the expression of Bax was increased. However, the $\mathrm{Bax} / \mathrm{Bcl}-2$ ratio was increased in the LN+TFP group (Fig. 4C)

Effect of TFP on renal function in $L N$ mice. The effect of TFP on renal function in LN mice was investigated. The level of BUN was significantly higher in the LN group $(22.84 \pm 0.56 \mathrm{mM})$, compared with that in the normal group $(16.57 \pm 3.46 \mathrm{mM})$. However, the level of BUN was significantly decreased in the TFP-treated LN mice $(19.99 \pm 0.92 \mathrm{mM})$ (Fig. 5A). The serum Cr levels exhibited the same trend, with levels of $143.54 \pm 23.35,237.19 \pm 13.70$ and $210.56 \pm 36.26 \mu \mathrm{M}$ in the normal, LN and LN+TNF groups, respectively (Fig. 5B). These data confirmed that TFP improved the renal function in $\mathrm{LN}$ mice.

TFP toxic effects of TFP in LN mice. The present study also performed drug toxicity experiments with TFP in vivo. The level of AST was significantly higher in the LN group

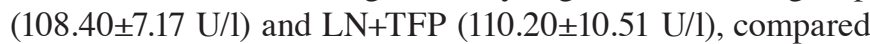
with that in the normal group $(72.18 \pm 6.13 \mathrm{U} / \mathrm{l})$. However, no significant differences were found between the LN group and TFP-treated LN group (Fig. 6A). No significant differences in body weight change (post-pre) were observed between the mice in the LN group $(5.12 \pm 1.07 \mathrm{~g})$ and those in the TFP-treated LN group $(5.07 \pm 0.77 \mathrm{~g})$ (Fig. 6B). These results indicated that the intraperitoneal administration of TFP did not produce marked toxic effects in LN mice. 
A
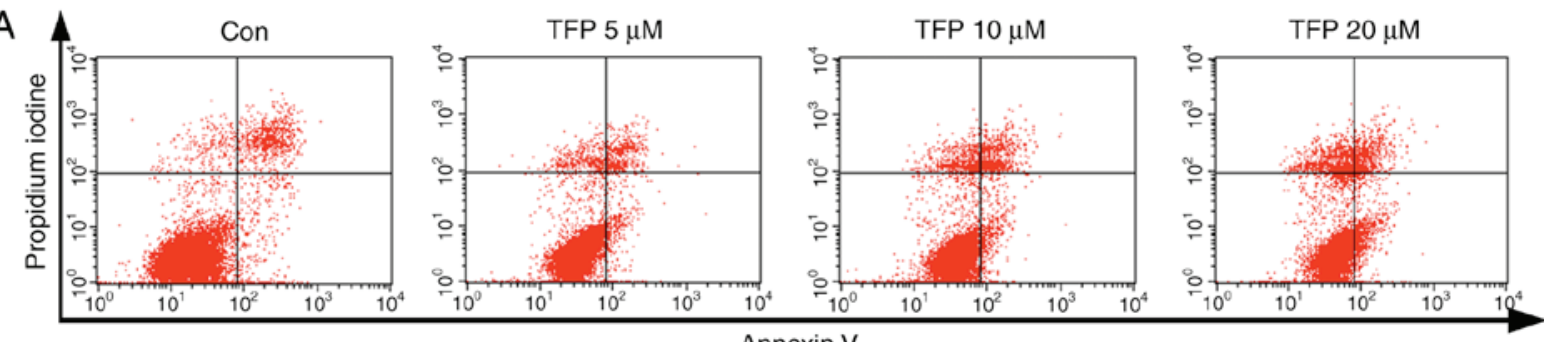

Annexin V

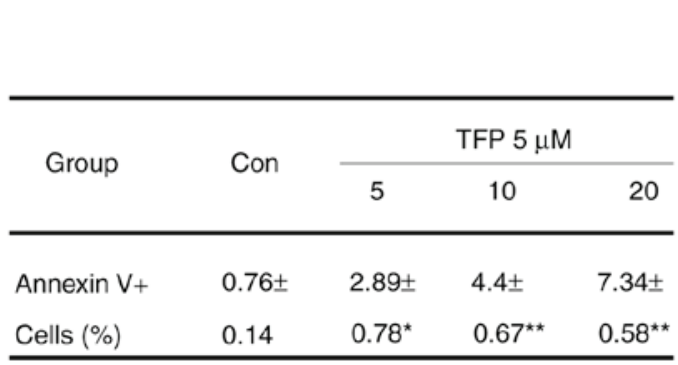

B
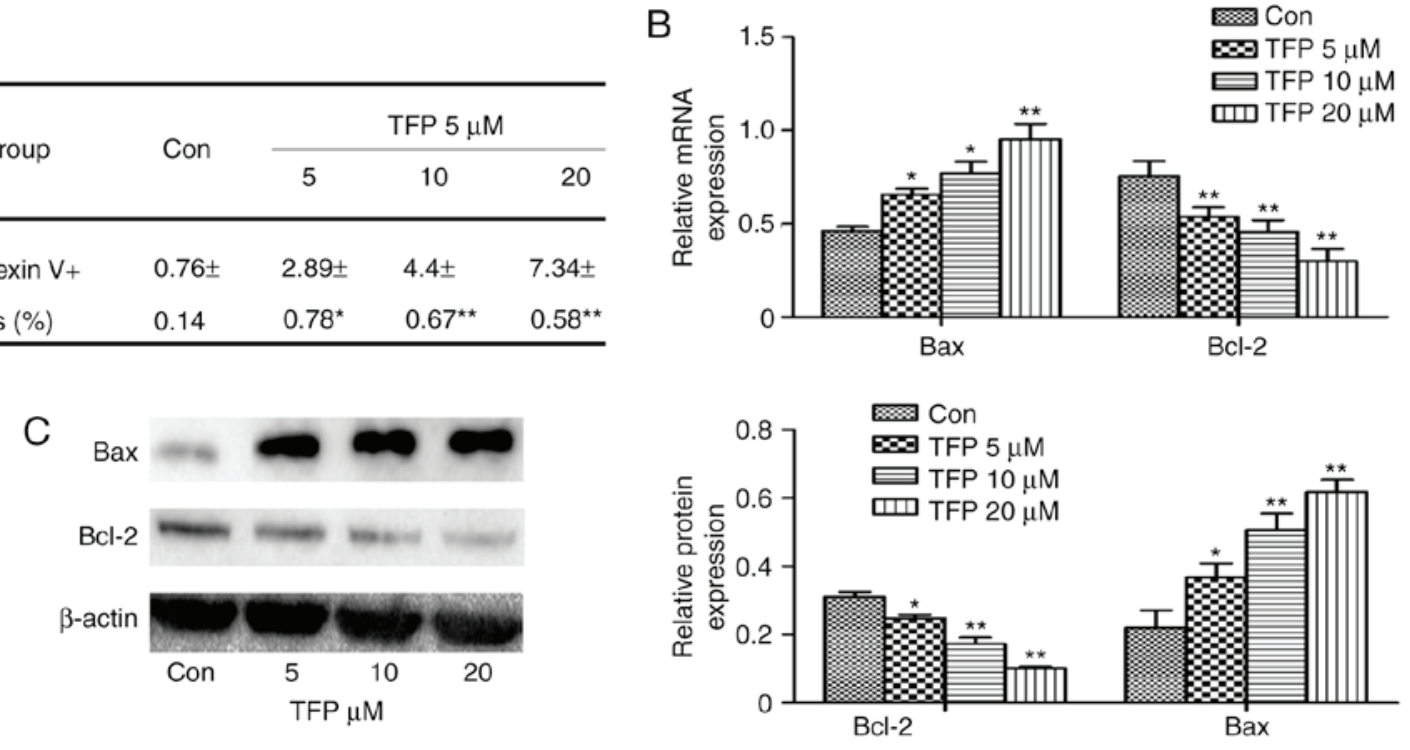

Figure 2. TFP promotes MC apoptosis in vitro. MCs were treated with various concentrations ( 0,5 , 10 and $20 \mu \mathrm{M})$ of TFP for $24 \mathrm{~h}$. (A) Cell apoptotic rate was detected using an Annexin V/propidium iodide apoptosis assay. (B) mRNA expression levels of Bcl-2 and Bax were detected using reverse transcription-quantitative polymerase chain reaction analysis. (C) Protein expression levels of Bcl-2 and Bax were detected using western blot analysis. All data are presented as the means \pm standard deviation of three separate experiments $(n=3)$. ${ }^{*} \mathrm{P}<0.05$ and ${ }^{* *} \mathrm{P}<0.01$, vs. con. MCs, mesangial cells; TFP, trifluoperazine; con, control; Bcl-2, B-cell lymphoma-2; Bax, Bcl-2-associated X protein.

Reduced protein expression of AKT in MCs by TFP. The results of the western blot analysis showed that TFP significantly and dose-dependently decreased the level of p-AKT in MCs, compared with that in the control group (Fig. 7A). To further examine whether TFP inhibited the AKT pathways associated with apoptosis, PDGF was used to stimulate MCs. PDGF induced the phosphorylation of AKT, decreased the levels of Bcl-2 and increased the expression of Bax. However, following treatment with TFP, the opposite trend was observed (Fig. 7B). These data demonstrated that TFP inhibited the AKT pathways and this may be involved in the TFP-induced apoptosis of MCs.

\section{Discussion}

The present study examined whether TFP had a potential effect on the activity of MCs. It was found that TFP applied in vitro and in vivo significantly inhibited the proliferation of MCs, induced apoptosis and improved renal function in MRL/lpr LN mice without exhibiting any major adverse effects. These analyses showed that TFP inhibited the expression of p-AKT, indicating that TFP may inhibit MCs through promoting apoptosis, at least in part via the AKT signaling pathway.

The proliferation of MCs induced by various factors is detrimental as it accelerates kidney damage and promotes glomerulosclerosis. Therefore, the inhibition of $\mathrm{MC}$ proliferation has emerged as an important treatment option for proliferative glomerular diseases. Several previous studies (18-20) have shown that TFP can inhibit the proliferation of cancer cells. In the present study, it was found that TFP also inhibited the MC proliferation in vitro, as shown in Fig. 1.

Apoptosis is a genetically programmed cell death and has a key function in the repair process evoked by proliferative diseases. In the repair process during inflammation caused by proliferative renal disease, apoptosis avoids the excessive proliferation of MCs (24). Bcl-2 and Bax proteins are the two principal members of the Bcl-2 multi-gene family. Bcl-2 prevents apoptosis, whereas Bax produces a pro-apoptotic effect (25). The present study revealed that TFP treatment resulted in notable rises in Annexin V-positive cell populations and augmented the $\mathrm{Bax} / \mathrm{Bcl}-2$ ratio in a dose-dependent manner, as shown in Fig. 2. These results are consistent with those reported for TFP in other diseases and tissue types $(19,21,26)$. The present study showed that TFP upregulated the ratio of $\mathrm{Bax} / \mathrm{Bcl}-2$ to promote $\mathrm{MC}$ apoptosis in vitro.

The present study also confirmed that TFP inhibited normal MC proliferation by promoting the apoptosis pathways described above. A higher concentration of serum (20\% FBS) was used to stimulate MCs and cause them to proliferate abnormally, prior to treating the MCs with TFP to antagonize the effect. The results showed that high concentrations of serum accelerated cell proliferation and inhibited cell apoptosis. 

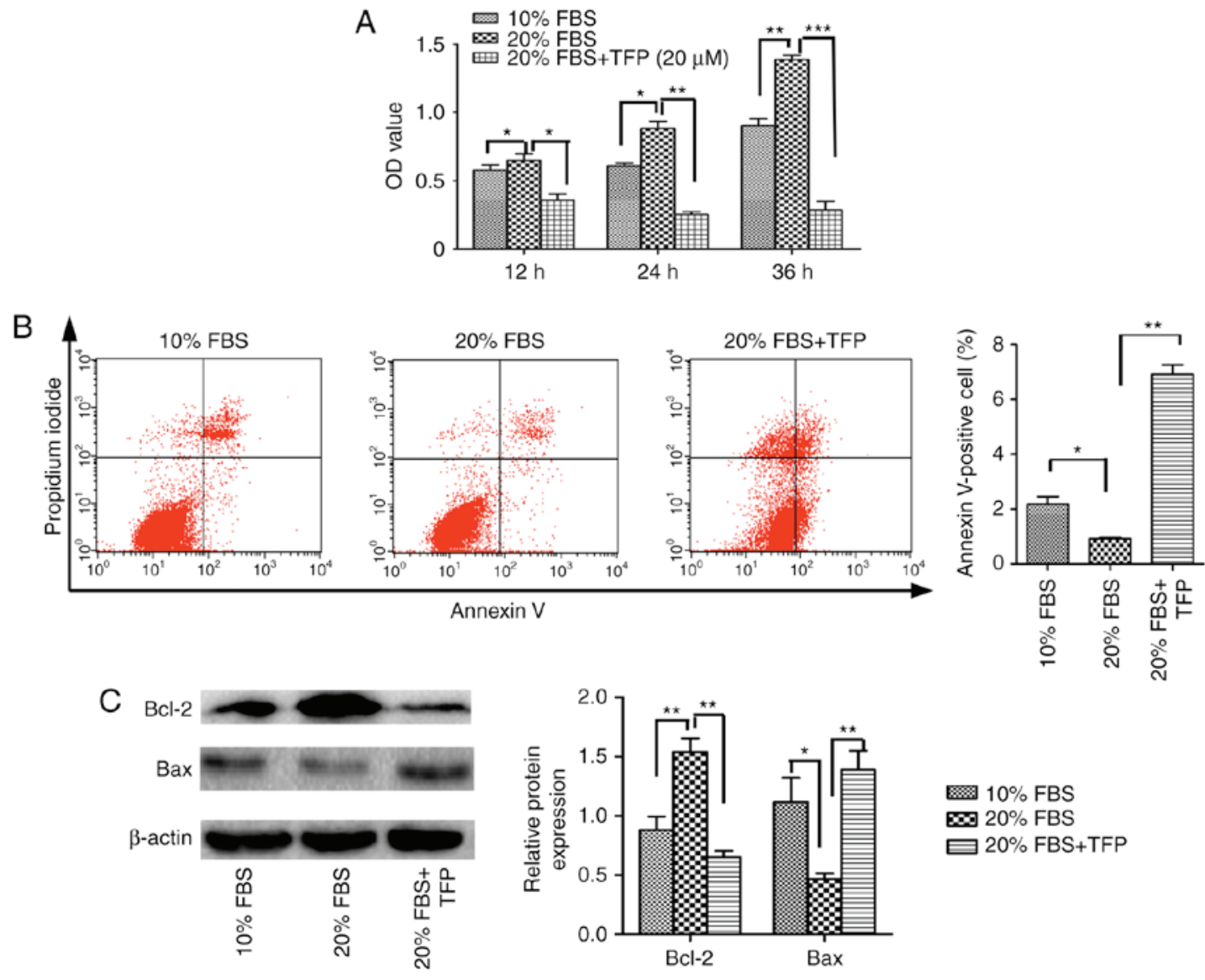

Figure 3. Effect of TFP on cell apoptosis, and protein expression of Bcl-2 and Bax in MCs stimulated to proliferate with 20\% FBS. (A) TFP antagonized $20 \%$ FBS-stimulated MC proliferation. Cell viability was detected using a cell counting kit-8. (B) Flow cytometry was used to analyze the apoptosis of MCs exposed to $20 \%$ FBS treated with TFP $(20 \mu \mathrm{mol} / \mathrm{l})$ for $24 \mathrm{~h}$. (C) Protein expression levels of Bcl-2 and Bax were detected using western blot analysis. All data are presented as the mean \pm standard deviation of three separate experiments $(\mathrm{n}=3)$. ${ }^{*} \mathrm{P}<0.05,{ }^{* * *} \mathrm{P}<0.01$ and ${ }^{* * * *} \mathrm{P}<0.001$. MCs, mesangial cells; TFP, trifluoperazine; Bcl-2, B-cell lymphoma-2; Bax, Bcl-2-associated X protein; OD, optical density.

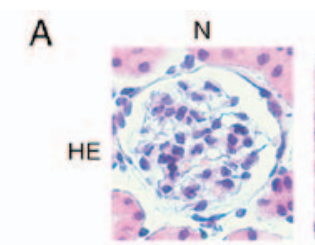

B

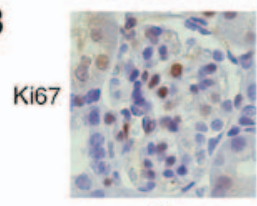

$\mathrm{N}$
LN
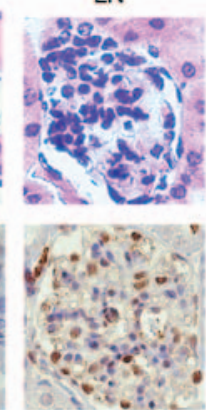

LN
LN+TFP
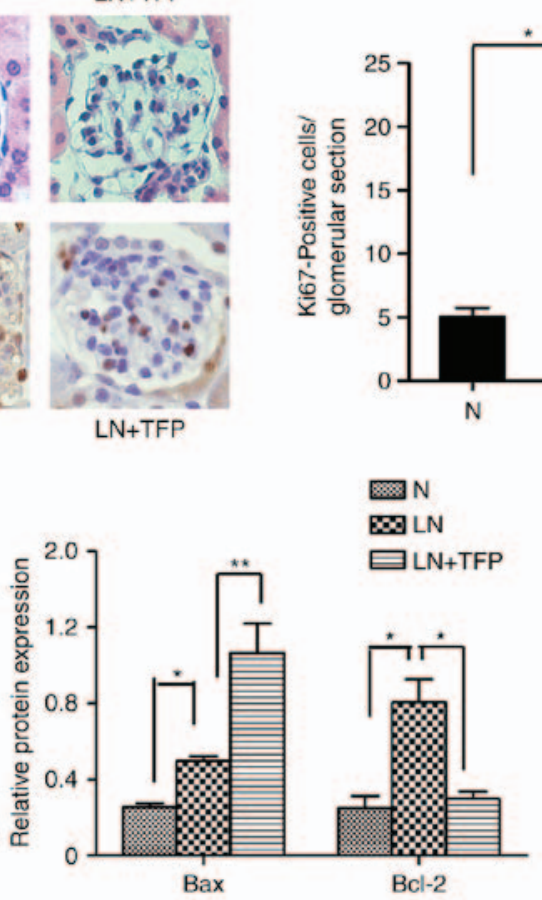
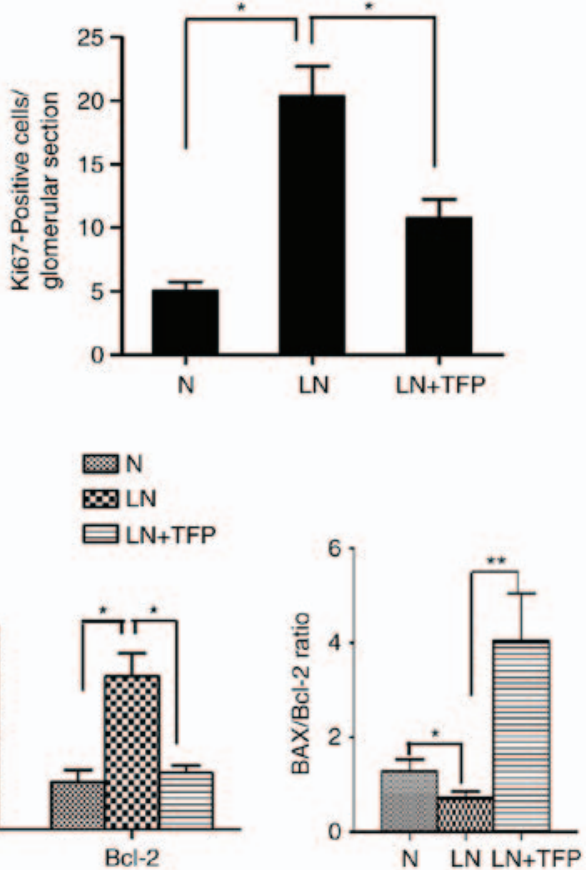

Figure 4. TFP promotes cellular apoptosis in LN mice in vivo. (A) H\&E staining (magnification, $\mathrm{x} 400$ ). (B) Ki67 immunohistochemistry (magnification, $\mathrm{x} 400$ ). (C) Protein expression levels of Bcl-2 and Bax were analyzed using western blot analysis ( $\mathrm{n}=6$ ). ${ }^{*} \mathrm{P}<0.05$ and ${ }^{* *} \mathrm{P}<0.001$, vs. LN. N, normal; $\mathrm{LN}$, lupus nephritis; MCs, mesangial cells; TFP, trifluoperazine; Bcl-2, B-cell lymphoma-2; Bcl-2-associated X protein; H\&E, hematoxylin and eosin. 

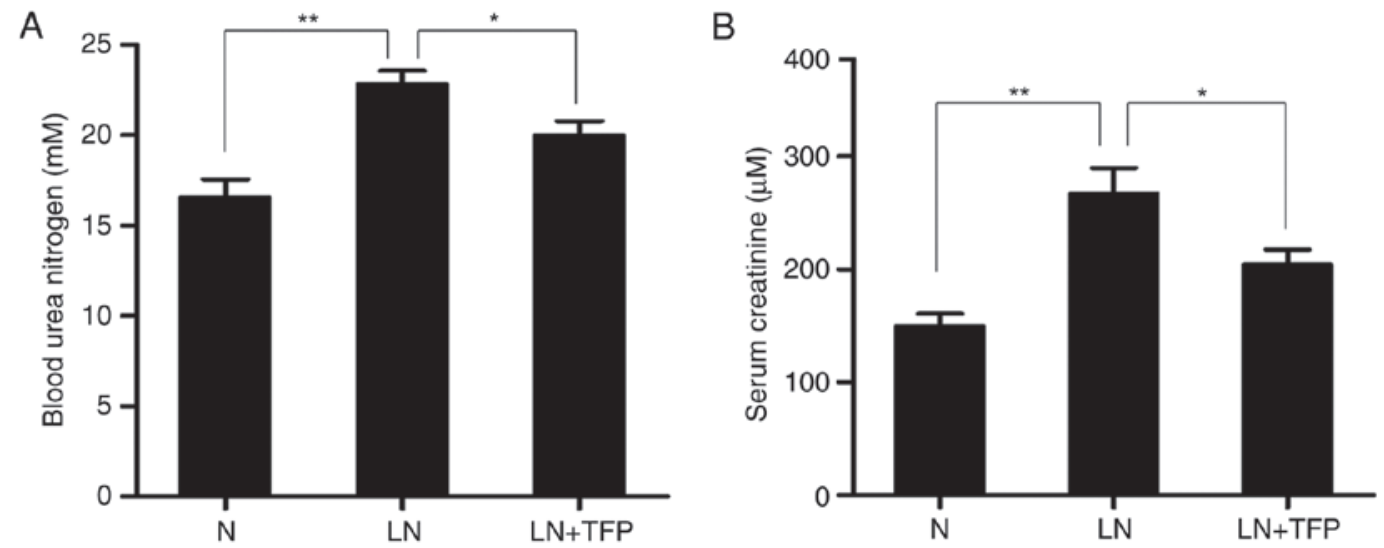

Figure 5. (A and B) TFP reduces levels of urea nitrogen and creatinine in serum of $L N$ mice. Data are presented as the mean \pm standard deviation $(n=6)$. ${ }^{*}<0.05$ and ${ }^{* *} \mathrm{P}<0.001$ vs. LN. N, normal; LN, lupus nephritis; TFP, trifluoperazine.

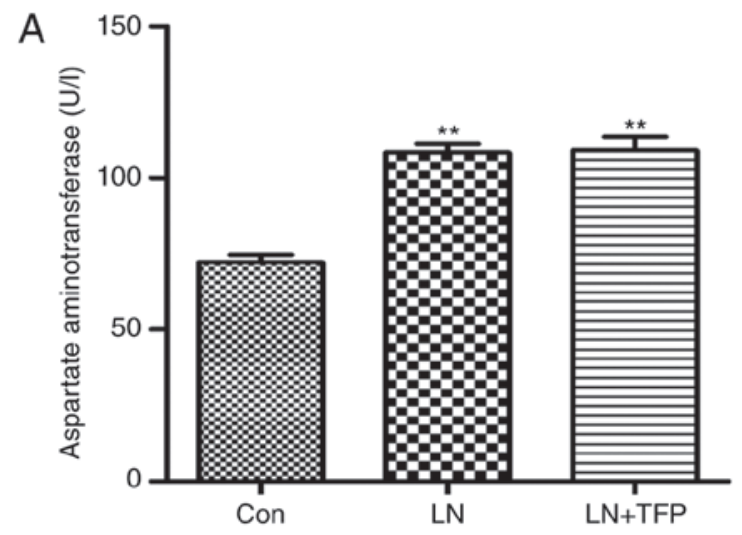

$\mathrm{B}$

\begin{tabular}{ccll}
\hline Group $(\mathrm{g})$ & Pre-treatment & Post-treatment & Post-Pre \\
\hline Con & $20.61 \pm 1.71$ & $28.29 \pm 1.27$ & $7.68 \pm 1.30$ \\
LN & $20.56 \pm 1.64$ & $25.68 \pm 1.10^{\star \star}$ & $5.12 \pm 1.07^{\star \star}$ \\
LN+TFP & $19.92 \pm 0.96$ & $24.98 \pm 0.57^{\star \star}$ & $5.07 \pm 0.77^{\star \star}$ \\
\hline
\end{tabular}

Figure 6. Effect of TFP on liver function and body weight of LN mice. (A) TFP had no effect on the level of aspartate aminotransferase in the serum of LN mice. (B). TFP had no effect on body weight changes in LN mice. Data are presented as the mean \pm standard deviation $(n=6) .{ }^{* *} \mathrm{P}<0.001$, vs. Con. Con, control; LN, lupus nephritis; TFP, trifluoperazine.

However, the use of TFP together with a high concentration of serum in the cell resulted in the cell proliferation rate being $<20 \%$ of that in the serum culture group with the additional promotion of cell apoptosis, as shown in Fig. 3. Therefore, TFP antagonized the abnormal proliferation of MCs induced by exogenous factors in vitro.

For the in vivo experiment, an MRL/lpr LN mouse model was used to examine the effect of TFP on MCs. As shown in Fig. 4A and B, the data showed that TFP inhibited the abnormal proliferation of MCs in the LN mice. It was observed that the protein expression levels of Bax and Bcl-2 were higher in the LN mice, compared with those in the normal mice. This result was consistent with a study by Cui et al (27). The present study aimed to further understand the underlying factors, and it was found that the ratio of Bax/Bcl-2 was lower in LN mice, compared with that in normal group mice. This suggested that Bcl-2 was more important in inhibiting the apoptosis of MCs in LN, compared with Bax. Following TFP treatment, the ratio of Bax/Bcl-2 was upregulated, which promoted apoptosis. The findings in vivo were consistent with those in vitro. These results revealed that TFP upregulated the ratio of $\mathrm{Bax} / \mathrm{Bcl}-2$ to promote $\mathrm{MC}$ apoptosis.

The activation of MCs can lead to damage to renal function, therefore, the present study investigated whether TFP can alleviate renal pathological injury and improve renal function following inhibiting MCs. The, two blood measurements of BUN and serum $\mathrm{Cr}$ are important indicators of renal function as they are easily measured. An increase in these indicators in the blood predicts significant damage to functioning nephrons. In the present study, the levels of these indicators indicated severe injury in the LN mice group; a salient decrease was observed following TFP treatment $(20 \mathrm{mg} / \mathrm{kg} \cdot$ day for 12 weeks), as shown in Fig. 5. These results indicated that TFP slowed the progression of $\mathrm{LN}$ in the model mice and was accounted for by the inhibited proliferation of MCs. Of note, no significant changes in behavior, mental state, diet or 
A

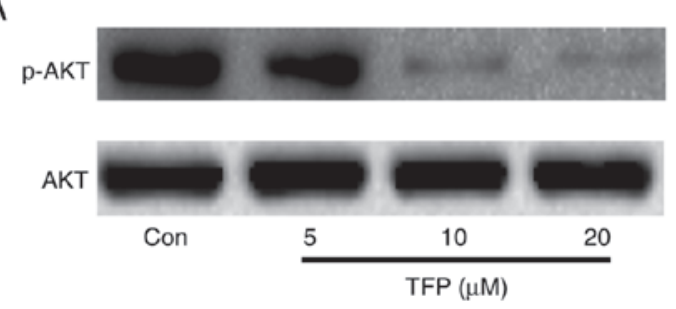

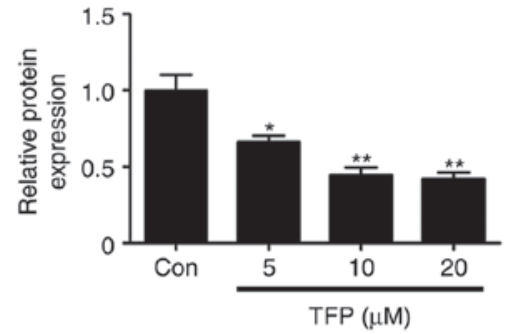

$\operatorname{TFP}(\mu \mathrm{M})$
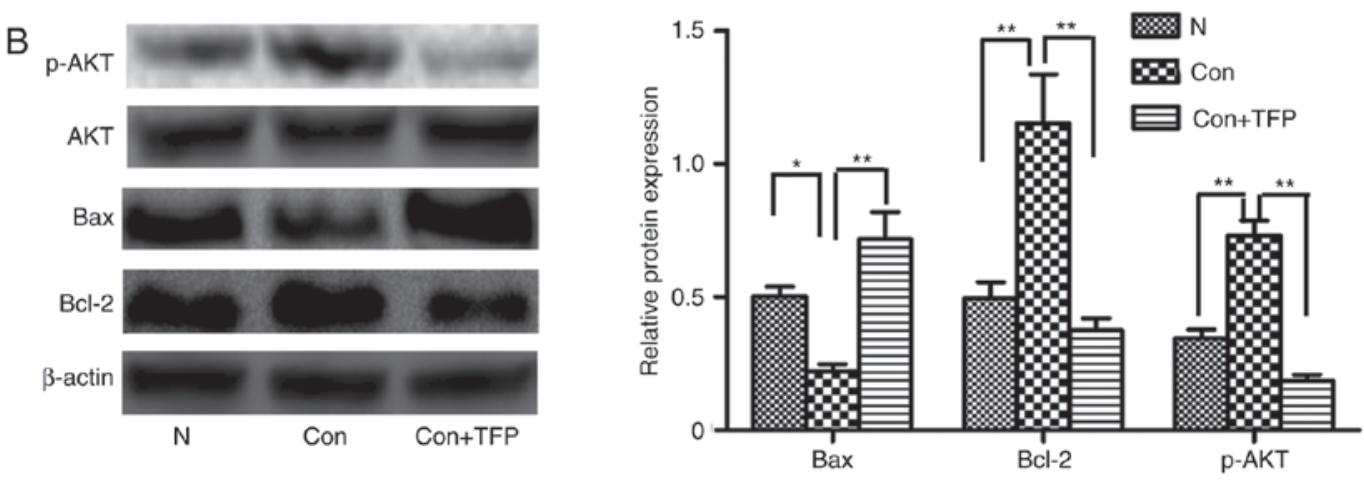

Figure 7. TFP-mediated inhibition of the phosphorylation of AKT. (A) MCs were treated with various concentrations $(0,5,10$ and $20 \mu \mathrm{M})$ of TFP for $24 \mathrm{~h}$. Protein levels of AKT and p-AKT were determined using western blot analysis. Data are expressed as the mean \pm standard deviation of six experiments per group ( $\mathrm{n}=6),{ }^{*} \mathrm{P}<0.05$ and ${ }^{* *} \mathrm{P}<0.001 \mathrm{vs}$. Con. (B) MCs were induced by platelet-derived growth factor $(20 \mathrm{ng} / \mathrm{ml})$ for $24 \mathrm{~h}$ with or without TFP $(20 \mu \mathrm{M})$ treatment. Effects of TFP on protein expression levels of p-AKT, Bcl-2 and Bax in the MCs were determined using western blot analysis. Data are expressed as the mean \pm standard deviation of six experiments per group. $(\mathrm{n}=6)$. ${ }^{*} \mathrm{P}<0.05$ and ${ }^{* *} \mathrm{P}<0.001$ vs. Con. MCs, mesangial cells; TFP, trifluoperazine; Con, control; Bcl-2, B-cell lymphoma-2; Bcl-2-associated X protein; p-, phosphorylated.

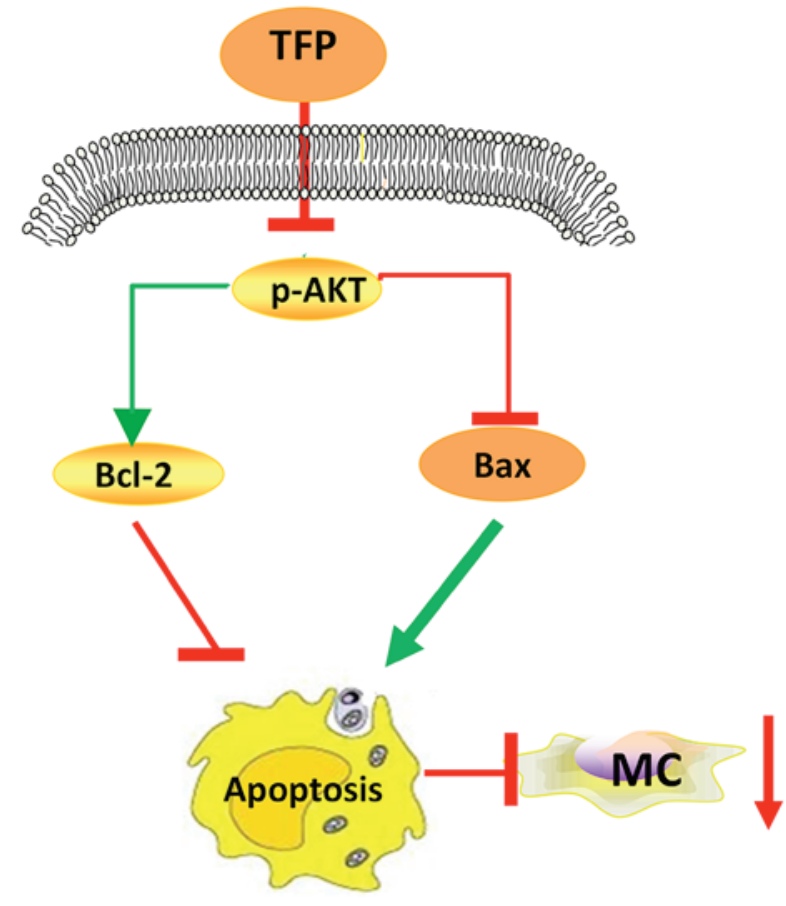

Figure 8. Proposed mechanisms of the effects of TFP on MC proliferation through cell apoptosis. MCs, mesangial cells; TFP, trifluoperazine; Bcl-2, B-cell lymphoma-2; Bcl-2-associated X protein; p-, phosphorylated.

sleep were observed following intraperitoneal administration of TFP in the LN mice. Compared with the control group, no significant differences in liver function or change in body weight were found between the LN group and TFP-treated LN group, as shown in Fig. 6.
AKT is a serine/threonine kinase, which is important in the regulation of cell proliferation, survival/apoptosis, angiogenesis and protein synthesis $(28,29)$. In previous years, several reports have consistently observed that $\mathrm{AKT}$ is frequently activated among several types of cancer, initiating a potent anti-apoptotic signal (30). Shimamura et al reported that the proliferation of MCs in vitro was associated with the PI3K/AKT signaling pathway, which led to proliferation by inhibiting apoptosis (31). Gong et al reported that aplysin effectively inhibited the growth of a glioma and induced apoptosis via suppressing the PI3K/AKT signaling pathway (15). Therefore, the effect of TFP on MC apoptosis may also be associated with the PI3K/AKT signaling pathway. The present study aimed to elucidate this interaction and quantify the effect of TFP on the PI3K/AKT signaling pathway. The results of the present study showed that TFP significantly and dose-dependently decreased the levels of p-AKT, as shown in Fig. 7A. To further establish whether TFP can inhibit AKT pathways, PDGF was used to stimulate MCs as a positive control. This induces the phosphorylation of AKT and affects the AKT signaling pathway to decrease the level of apoptosis (32). The present study showed that, following treatment with TFP, the recorded trend was opposite to that observed in the PDGF group without TFP; a downregulation of $\mathrm{p}-\mathrm{AKT}$ and corresponding increases to the $\mathrm{Bax} / \mathrm{Bcl}-2$ ratio were observed, as shown in Fig. 7B. The findings revealed that TFP upregulated the levels of apoptosis, at least in part via suppressing AKT signaling pathways in MCs.

In conclusion, TFP inhibited the proliferation of human MCs in vitro and in vivo via promoting apoptosis (augmenting the $\mathrm{Bax} / \mathrm{Bcl}-2$ ratio), at least in part by suppressing the AKT signaling pathway (Fig. 8). Further investigations on the anti-proliferative efficiency of TFP and the underlying mecha- 
nisms are required to broaden this understanding. In continuation of the present study, future investigations aim to examine the effect of TFP on cell cycle. The Food and Drug Administration approval concerning TFP suggests that it is a safe drug to use in large populations and that it has manageable or tolerable side effects (33); therefore, these findings may provide a novel strategy for the treatment of LN.

\section{Acknowledgements}

This study was supported by the National Natural Science Foundation of China (grant nos. 81570626 and 81450033). The authors would like to thank Dr Xuewang Li of Peking Union Medical College Hospital for providing the human mesangial cells.

\section{Competing interests}

The authors declare that they have no competing interests.

\section{References}

1. Badr KF, Murray JJ, Breyer MD, Takahashi K, Inagami T and Harris RC: Mesangial cell, glomerular and renal vascular responses to endothelin in the rat kidney. Elucidation of signal transduction pathways. J Clin Invest 83: 336-342, 1989.

2. Wyatt RJ and Julian BA: IgA nephropathy. N Engl J Med 368: 2402-2414, 2013.

3. Grassmann A, Gioberge S, Moeller S and Brown G: ESRD patients in 2004: Global overview of patient numbers, treatment modalities and associated trends. Nephrol Dial Transplant 20: 2587-2593, 2005.

4. Matsumoto K, Yoshikai Y, Asano T, Himeno K, Iwasaki A and Nomoto K: Defect in negative selection in lpr donor-derived $\mathrm{T}$ cells differentiating in non-lpr host thymus. J Exp Med 173: 127-136, 1991.

5. Sugiyama N, Nakashima H, Yoshimura T, Sadanaga A, Shimizu S, Masutani K, Igawa T, Akahoshi M, Miyake K, Takeda A, et al: Amelioration of human lupus-like phenotypes in MRL/lpr mice by overexpression of interleukin 27 receptor alpha (WSX-1). Ann Rheum Dis 67: 1461-1467, 2008.

6. Lamoureux JL, Watson LC, Cherrier M, Skog P, Nemazee D and Feeney AJ: Reduced receptor editing in lupus-prone MRL/lpr mice. J Exp Med 204: 2853-2864, 2011.

7. Johnstone RW, Ruefli AA and Lowe SW: Apoptosis: A link between cancer genetics and chemotherapy. Cell 108: 153-164, 2002.

8. Brunelle JK and Letai A: Control of mitochondrial apoptosis by the Bcl-2 family. J Cell Sci 122: 437-441, 2009.

9. Czabotar PE, Lessene G, Strasser A and Adams JM: Control of apoptosis by the BCL-2 protein family: Implications for physiology and therapy. Nat Rev Mol Cell Biol 15: 49-63, 2014.

10. Uda S, Yoshimura A, Sugenoya Y, Inui K, Taira T and Ideura T: Mesangial proliferative nephritis in man is associated with increased expression of the cell survival factor, Bcl-2. Am J Nephrol 18: 291-295, 1998.

11. Zhuan B, Ding Y, Zhang H and Yu Y: Effects of Xueniaoting powder and S-9 on apoptosis and expression of bax and bcl-2 in glomerular mesangial cells. Shenzhen J Integ Trad Chin Western Med 13: 447-456, 2003.

12. Zhuan B, Ding Y and Wu L: Effects of shenbining on apoptosis and experssion of bax and $\mathrm{Bcl}-2$ in the kidney of mesangial proliferative glomerulonephritis. Chin J Integ Trad Western Nephrol, 4: 316-318, 2003.

13. Franke TF, Hornik CP, Segev L, Shostak GA and Sugimoto C: PI3K/Akt and apoptosis: Size matters. Oncogene 22: 8983-8998, 2003.

14. Gao T, Furnari F and Newton AC: PHLPP: A phosphatase that directly dephosphorylates Akt, promotes apoptosis, and suppresses tumor growth. Mol Cell 18: 13-24, 2005.
15. Gong AJ, Gong LL, Yao WC, Ge N, Lu LX and Liang H: Aplysin induces apoptosis in glioma cells through HSP90/AKT pathway. Exp Biol Med (Maywood) 240: 639-644, 2015.

16. Chen WS, Xu PZ, Gottlob K, Chen ML, Sokol K, Shiyanova T, Roninson I, Weng W, Suzuki R, Tobe K, et al: Growth retardation and increased apoptosis in mice with homozygous disruption of the Akt1 gene. Genes Dev 15: 2203-2208, 2001.

17. Stylianou K, Petrakis I, Mavroeidi V, Stratakis S, Vardaki E, Perakis K, Stratigis S, Passam A, Papadogiorgaki E, Giannakakis K, et al: The PI3K/Akt/mTOR pathway is activated in murine lupus nephritis and downregulated by rapamycin. Nephrol Dialy Transplant 26: 498-508, 2011.

18. Gulino A, Barrera G, Vacca A, Farina A, Ferretti C, Screpanti I, Dianzani MU and Frati L: Calmodulin antagonism and growth-inhibiting activity of triphenylethylene antiestrogens in MCF-7 human breast cancer cells. Cancer Res 46: 6274-6278, 1986.

19. Chen QY, Wu LJ, Wu YQ, Lu GH, Jiang ZY, Zhan JW, Jie Y and Zhou JY: Molecular mechanism of trifluoperazine induces apoptosis in human A549 lung adenocarcinoma cell lines. Mol Med Rep 2: 811-817, 2009.

20. Polischouk AG, Holgersson A, Zong D, Stenerlöw B, Karlsson HL, Möller L, Viktorsson K and Lewensohn R: The antipsychotic drug trifluoperazine inhibits DNA repair and sensitizes non small cell lung carcinoma cells to DNA double-strand break induced cell death. Mol Cancer Ther 6: 2303-2309, 2007.

21. Yeh CT, Wu AT, Chang PM, Chen KY, Yang CN, Yang SC, Ho CC, Chen CC, Kuo YL, Lee PY, et al: Trifluoperazine, an antipsychotic agent, inhibits cancer stem cell growth and overcomes drug resistance of lung cancer. Am J Respir Crit Care Med 186: 1180-1188, 2012.

22. Delarue F, Virone A, Hagege J, Lacave R, Peraldi MN, Adida C, Rondeau E, Feunteun J and Sraer JD: Stable cell line of T-SV40 immortalized human glomerular visceral epithelial cells. Kidney Int 40: 906-912, 1991.

23. Livak KJ and Schmittgen TD: Analysis of relative gene expression data using real-time quantitative PCR and the 2(-Delta Delta C(T)) method. Methods 25: 402-408, 2001.

24. Savill J, Mooney A and Hughes J: Apoptosis and renal scarring. Kidney Int Suppl 54: S14-S17, 1996.

25. Adams JM and Cory S: The Bcl-2 protein family: Arbiters of cell survival. Science 281: 1322-1326, 1998.

26. Hong SH, Lee MY, Shin KS and Kang SJ: Perphenazine and trifluoperazine induce mitochondria-mediated cell death in SH-SY5Y cells. Animal Cells Syst 16: 20-26, 2012.

27. Cui JH, Qiao Q, Guo Y, Zhang YQ, Cheng H, He FR and Zhang J: Increased apoptosis and expression of FasL, Bax and caspase-3 in human lupus nephritis class II and IV. J Nephrol 25: 255-261, 2012

28. Fresno Vara JA, Casado E, de Castro J, Cejas P, Belda-Iniesta C and González-Barón M: PI3K/Akt signalling pathway and cancer. Cancer Treat Rev 30: 193-204, 2004.

29. Kim AH, Khursigara G, Sun X, Franke TF and Chao MV: Akt phosphorylates and negatively regulates apoptosis signal-regulating kinase 1. Mol Cell Biol 21: 893-901, 2001.

30. Majumder PK and Sellers WR: Akt-regulated pathways in prostate cancer. Oncogene 24: 7465-7474, 2005.

31. Shimamura H, Terada Y, Okado T, Tanaka H, Inoshita $S$ and Sasaki S: The PI3-kinase-Akt pathway promotes mesangial cell survival and inhibits apoptosis in vitro via NF-kappa B and Bad. J Am Soc Nephrol 14: 1427-1434, 2003.

32. Franke TF, Yang SI, Chan TO, DattaK,Kazlauskas A,Morrison DK, Kaplan DR and Tsichlis PN: The protein kinase encoded by the Akt proto-oncogene is a target of the PDGF-activated phosphatidylinositol 3-kinase. Cell 81: 727-736, 1995.

33. Howland RH: Trifluoperazine: A sprightly old drug. J Psychosoc Nurs Ment Health Serv 54: 20-22, 2016.

This work is licensed under a Creative Commons Attribution-NonCommercial-NoDerivatives 4.0 International (CC BY-NC-ND 4.0) License. 